\title{
A third type of job search behavior: the use of the formal-informal joint channel in matching individual qualifications with hiring requirements in urban China
}

\author{
Jing Shen
}

\footnotetext{
Correspondence: jing.shen@uleth.ca The Prentice Institute for Global Population and Economy, University of Lethbridge, Lethbridge, Canada
}

\begin{abstract}
This study highlights the necessity of distinguishing the use of the formal-informal joint channel from the sole reliance on either the formal or informal job search channel. I first used interview data collected in three Chinese cities as well as ethnographic case studies in the existing literature to illustrate a typology of the distribution of job search behavior, by focusing on the match between individual qualifications and employers' hiring requirements. Based on data drawn from the 2003 China General Social Survey, the subsequent quantitative analysis confirms that neither the formal nor the informal job search channel dominates individual job search behaviors in practice. Rather, the formal-informal joint channel is used most frequently. Quantitative findings also show that competitive individual job seekers who possess both certifiable and non-certifiable qualifications are more likely to jointly use formal and informal job search methods. This study confirms that contact use plays a positive role in job searches, but very often in combination with the use of formal job search methods, rather than being used alone.
\end{abstract}

\section{Background}

Since Granovetter's $(1973,1974)$ seminal study demonstrated the importance of personal ties in individual job searches, informal job search methods have been widely studied across societies (Bian 1997; Boxman et al. 1991; Campbell and Rosenfeld 1985; Erickson 2001; Flap and Boxman 1999; Lin and Dumin 1986; Marsden and Campbell 1990; Volker and Flap 1999; Wegener 1991). A commonly adopted approach is to examine the positive effects of informal job search methods by focusing only on a single type of job search behavior. For example, from the employer's perspective, the use of internal referrers has been demonstrated to be more efficient than the formal recruitment channel in matching potential employees with job positions (Fernandez et al. 2000; Fernandez and Weinberg 1997; Rees 1966). By focusing on the variation in tie strengths, scholars have also reached an agreement about the positive role that weak ties play in information flow (Granovetter 1973, 1974, 1995; Lai et al. 1998; Lin and Dumin 1986) and that strong ties play in influence flow (Bian 1997; Bian and Ang 1997).

Despite the insights contributed by the existing studies, the approach of comparing different types of single job search methods does not accurately reflect individuals'

(c) 2015 Shen; licensee Springer. This is an Open Access article distributed under the terms of the Creative Commons Attribution License (http://creativecommons.org/licenses/by/4.0), which permits unrestricted use, distribution, and reproduction in any medium, provided the original work is properly credited. 
job-seeking behavior in reality. In a recent study, Shen points out that "although individual job seekers usually mobilize social contacts and follow the informal application procedures simultaneously, the use of informal job search methods is usually considered separately from that of formal channels in the existing studies" (Shen $2014,1)$. This study highlighted that failing to consider contact use in combination with formal job search methods directly causes the long-lasting unsolved debate in the existing literature about whether contact use plays a positive role in job searches. By using the 2003 China General Social Survey, Shen (2014) demonstrate that the joint use of formal and informational channels leads to better job search outcomes (measured by the likelihood of job search success within 3 months and income obtainment), as compared to the use of either the formal or informal job search channel alone.

What remains unsolved, however, is the "why" question. A theoretical explanation is needed in addition to one's intuitive sense about the advantages of the combined use of formal and informal job search channels relative to using either of the single types. Thus, the purpose of this study is to theoretically elaborate on and empirically demonstrate the necessity of distinguishing the formal-informal joint job search channel from the two single channels.

Theoretically, I propose to situate individual job search behaviors in the job-person matching process, through which a candidate's qualifications are matched with the employer's hiring requirements. I theorize on a typology of the distribution of individual job search behaviors, which will predict that the formal-informal joint channel, rather than the formal or the informal channel alone, is the most frequently used job search method. This theoretical distribution is supported by empirical evidence from urban China. By using interview data collected in three representative Chinese cities, this study explains exactly how formal and informal methods are used jointly as well as separately in various job-person matching scenarios. I then draw data from a countrywide survey to show that individuals with different types of qualifications present different job search patterns. The combined qualitative and quantitative analyses show the significant importance of the use of the formal-informal joint channel in matching individual qualifications and hiring requirements of job positions, at least in the complex job-person matching context of urban China.

\section{A focus on the hiring requirements of job positions}

Job seekers in various labor markets often use informal methods to find jobs, such as by getting help with interview preparation from family members and relatives, accessing job information through acquaintances, or having internal employees put in a good word for them (Bian 1997; Bian and Ang 1997; Flap and Boxman 1999; Lin et al. 1981). However, studies focusing on the job seeker's side have not yet clearly addressed the debate about whether contact use exerts a positive impact on job search success or whether job search success through contact use simply reflects the homophily principle of social capital. The latter implies a spurious association between contact use and job search outcomes since people tend to make friends with others similar to themselves (Mouw 2003).

Only when the informal channel is examined from the employer's perspective have the positive effects of contact use been consistently substantiated. Using data 
collected in a large retail bank and a phone center, Fernandez and his associates (Fernandez et al. 2000; Fernandez and Weinberg 1997; Marsden and Gorman 2001) scrutinize multiple phases of the hiring process and demonstrate that using preexisting social ties facilitates job-person matching success at each stage of the hiring process. Their studies show that external referrals are able to prepare more suitable resumes and time their applications better than non-referrals at early stages and that they are also more likely to receive interviews and job offers at late stages of a hiring process. These findings suggest that social ties should be viewed as "a formal means by which the firm seeks to harness the power of social relations for its own ends" (Fernandez and Weinberg 1997, 900). Since job search channels that lead to positive search results are those that well match the employer's hiring methods, it is necessary to consider the variation in individual job search behaviors based on the variation in employers' hiring methods, which are essentially determined by hiring requirements for job positions.

\section{Typology in matching individual qualifications and hiring requirements}

An employer's goal is to hire a candidate who best suits the requirements of a vacant position. According to Marsden's (1994a, 1994b) studies on the wave of the National Organizations Study (NOS) in the early 1990s, a hiring process can be roughly divided into two stages: recruitment (or extensive search) and selection (or intensive search) (see also Rees 1966). At the recruitment stage, an employer's goal is to "publicize the availability of openings to qualified applicants and assemble modest information about a pool of eligible persons" (Marsden 1994b, 288). After a candidate pool is generated, the employer then evaluates all applicants to single out the candidates who best match the requirements of the vacant position. Eventually, "the staffing process ends with the negotiation of agreements between organizations and employees" (Marsden 1994b, 288).

Other job search studies (Weber and Mahringer 2008; Zikic and Saks 2009) focus on the multidimensional evaluation criteria or job requirements involved in the hiring process. Despite the variation, job requirements can roughly be categorized into two groups from the perspective of "certifiability." "Certifiability" means the extent to which a required qualification can be measured, quantified, or proven by an authorized third party. Some requirements, such as job-related knowledge, are certifiable by diplomas, degrees, certificates, or licenses, while others, such as loyalty, work ethic, career ambition, enthusiasm, and personality, cannot be easily certified. At the recruitment stage, the employer's interest in candidates' certifiable qualifications may lead to the use of formal methods, such as listing specific requirements in advertisements. However, informal methods, such as coworkers or business/professional colleagues vouching for new hires are sometimes more effective at the recruitment stage if certain qualifications are difficult to evaluate by formal means. Likewise, at the selection stage, formal procedures (such as screening, testing, and interviewing) are used to evaluate candidates' certifiable qualifications (mainly indicated by education and work experience). However, informal methods are the most reliable way to gauge candidates' non-certifiable qualifications that cannot be measured explicitly, such as work ethic, suitability to the work environment, and compatibility with existing employees. In short, hiring is a complex process that involves matching 
individual qualifications and job requirements in both certifiable and non-certifiable dimensions, as well as in each hiring stage.

In an ideally dichotomized situation in which both the certifiability of hiring requirements and the stages of a hiring process are clearly divided, a two-by-two theoretical distribution of job-person matching methods can be constructed. Four types of job-person matching scenarios are generated accordingly: certifiable qualifications are desired at both recruitment and selection stages (type I), certifiable qualifications are required in recruitment with non-certifiable qualifications required in selection (type II), non-certifiable qualifications are preferred in recruitment with certifiable qualifications referred in selection (type III), and non-certifiable qualifications are desired at both the recruitment and selection stages (type IV). Correspondingly, Fig. 1 presents the typology of individual job search behaviors in the abovementioned four types of job-person matching scenarios. The formal job search channel will mainly be observed in both recruitment and selection stages in type I. The formal job search channel will dominate the recruitment stage with the dominance of the informal channel in the selection stage in type II. The informal channel will be mainly used in recruitment with the formal channel mainly seen in selection in type III, and finally, the informal channel will be the major method in both the recruitment and selection stages in type IV.

As shown in Fig. 1, type II and type III constitute $50 \%$ of the idealized job-person matching scenarios, meaning that in theory, one out of every two job-person matching cases requires the use of the formal-informal joint channel. The reality is certainly more complicated than the four types of idealized job-person matching scenarios. Recruitment and selection may not be distinctive in every hiring process, and the employer may not focus on only one type of qualification at each hiring stage. Freeing the dichotomized assumption about the stage of hiring would simplify the above typology by reducing the variation in a hiring process and thus does not require additional discussion. However, freeing the dichotomized assumption about the type of hiring requirements means that certifiable and non-certifiable qualifications can coexist in recruitment, selection, or both hiring stages.

Table 1 thus shows the extended typology of job search channels, with the coexistence of certifiable and non-certifiable requirements within each hiring stage taken into account. The possibility that both certifiable and non-certifiable qualifications are required in recruitment, in selection, or in both hiring stages requires a job seeker to maneuver formal and informal job search methods jointly in the corresponding hiring stage(s). As a result, the use of the formal-informal joint channel occurs not only between hiring stages (as

\begin{tabular}{|c|c|c|c|c|c|}
\hline \multirow[b]{2}{*}{ Type I } & Recruitment & Selection & Recruitment & Selection & \multirow{2}{*}{ Type II } \\
\hline & $\begin{array}{c}\text { Certifiable mainly } \\
\downarrow \\
\text { Formal }\end{array}$ & $\begin{array}{c}\text { Certifiable mainly } \\
\downarrow \\
\text { Formal }\end{array}$ & $\begin{array}{c}\text { Certifiable mainly } \\
\downarrow \\
\text { Formal }\end{array}$ & $\begin{array}{c}\text { Uncertifiable mainly } \\
\downarrow \\
\text { Informal }\end{array}$ & \\
\hline \multirow{2}{*}{ Type III } & Recruitment & Selection & Recruitment & Selection & \multirow[t]{2}{*}{ Type IV } \\
\hline & $\begin{array}{c}\text { Uncertifiable mainly } \\
\downarrow \\
\text { Informal }\end{array}$ & $\begin{array}{c}\text { Certifiable mainly } \\
\downarrow \\
\text { Formal }\end{array}$ & $\begin{array}{c}\text { Uncertifiable mainly } \\
\downarrow \\
\text { Informal }\end{array}$ & $\begin{array}{c}\text { Uncertifiable mainly } \\
\downarrow \\
\text { Informal }\end{array}$ & \\
\hline
\end{tabular}


Table 1 The extended typology of job search channels and hiring requirements

\begin{tabular}{lll}
\hline & Recruitment & Selection \\
\hline Single channel across two stages & Formal & Formal \\
& Informal & Informal \\
Joint channel between two stages & Formal & Informal \\
& Informal & Formal \\
Joint channel within two stages & Formal + Informal & Formal \\
& Formal + Informal & Informal \\
& Formal & Formal + Informal \\
& Informal & Formal + Informal \\
& Formal + Informal & Formal + Informal
\end{tabular}

demonstrated in type II and type III in Fig. 1), but more importantly, also within each hiring stage.

Under the assumption of the chance of the occurrence of each job search channel being equal, Table 1 presents the probability distribution of job search behaviors by including the possibility of the joint use of the formal and informal job search methods within each hiring stage. As a result, the chance of the occurrence of the use of the formal-informal joint channel in a job-person match is $78 \%(7 / 9)$, while the use of only the formal channel or only the informal channel each makes up $11 \%$ (1/ 9) of the theoretical probability distribution of job search behaviors. This theoretical distribution clearly shows that the conventional dichotomization of formal vs. informal job searches captures only a small portion of job search behaviors. The majority of job search cases in which formal and informal methods are used jointly have been overlooked under the formal vs. informal job search framework.

\section{Methods}

The following sections first use interview data and ethnographic cases in existing studies to illustrate the typology of the job search channels shown in Table 1. The interview data were collected in three Chinese cities, Beijing, Shenzhen, and Jiangyou, in summer 2009. The three selected urban locations represent the variations in the employment environment in urban China. Beijing represents tier 1 metropolitan cities with the greatest employment opportunities, in both the state and private sectors. Shenzhen represents tier 2 developed cities in which more employment opportunities are found in the private sector due to the fast economic growth in the newly emerging market sector. Jiangyou, a small city in the hinterland province of Sichuan, represents tier 3 cities in which employment opportunities are underdeveloped in both the state and private sectors. The qualitative illustration will show that job search behavior leads to job search success upon the match between individual job seekers' qualifications and employers' hiring requirements. To generalize the qualitative findings, I also drew data from the 2003 China General Social SurveyUrban Section (CGSS), a four-stage stratified probability sampling survey of the urban population with registered residency (hukou) status in mainland China. The quantitative analysis will substantiate the necessity of distinguishing the formalinformal joint channel from either type of single channel, by focusing on the 
likelihood of the use of job search channels among job seekers with different types of qualifications.

A focus on employment activities in urban China is particularly useful in studying the joint use of formal and informal job search methods. A wide range of job-person matching scenarios has been observed over the past three decades. The importance of guanxi (informal relations) has long been documented in the previous state-controlled job assignment system, even though employment was supposedly a formal procedure controlled by the state (Bian 1997). On the other hand, in the process of the emergence of a free labor market, the use of informal ties has been observed to be even more pervasive (Bian et al. 2005). Using data collected in the transitional context of urban China thus has a particular strength in highlighting the presence of the formal-informal joint channel in job-person matching activities.

\section{Empirical illustrations of the extended typology of job search behavior}

As mentioned above, in-depth interviews were conducted in three representative Chinese cities. By adopting the snowball sampling method, up to 50 urban residents with local hukou status were successfully accessed in each city. However, only interviewees who had entered their current workplace by 2003 were selected in order to match up with the time span covered by the quantitative analysis. As a result, 28 cases were used in this study, including 10 cases in Beijing and 9 cases in Shenzhen and Jiangyou, respectively. Descriptive statistics of all interview cases are shown in Appendix 1.

Among the 28 cases, 12 cases (43\%) reported using the formal-informal joint channel in their searches. Two cases $(7 \%)$ used the informal channel in recruitment and the formal channel in selection, seven cases $(25 \%)$ used the formal-informal joint channel in recruitment and only the formal channel in selection, and the remaining three $(11 \%)$ used the formal-informal joint channel in both recruitment and selection. Fourteen (50 \%) respondents reported using only the formal channel throughout their searches, consisting of 5 cases $(18 \%)$ in which jobs were assigned through the state-controlled job assignment system, with the remaining 9 (32\%) competing for publicly available jobs in the market. Only two respondents (7 \%) reported relying solely on the informal channel to obtain their jobs. One first worked as an intern in the local government before getting a permanent position in the same

Table 2 Distribution of job search behavior among 28 interviewees

\begin{tabular}{|c|c|c|c|c|c|}
\hline & Recruitment & Selection & Freq. (\%) & Subtypes & Freq. (\%) \\
\hline \multirow{2}{*}{$\begin{array}{l}\text { Single channel across } \\
\text { two stages }\end{array}$} & Formal & Formal & $14(50 \%)$ & $\begin{array}{l}\text { Assigned jobs from } \\
\text { the state }\end{array}$ & 5 (18\%) \\
\hline & Informal & Informal & 2 (7 \%) & $\begin{array}{l}\text { Jobs obtained from } \\
\text { the market }\end{array}$ & 9 (32\%) \\
\hline $\begin{array}{l}\text { Joint channel between } \\
\text { two stages }\end{array}$ & Informal & Formal & $2(7 \%)$ & & \\
\hline \multirow{2}{*}{$\begin{array}{l}\text { Joint channel within } \\
\text { two stages }\end{array}$} & $\begin{array}{l}\text { Formal + } \\
\text { Informal }\end{array}$ & Formal & 7 (25 \%) & & \\
\hline & $\begin{array}{l}\text { Formal + } \\
\text { Informal }\end{array}$ & $\begin{array}{l}\text { Formal }+ \\
\text { Informal }\end{array}$ & 3 (11\%) & & \\
\hline Total & & & $28(100 \%)$ & & \\
\hline
\end{tabular}


workplace, while the other found a job in the private sector. The distribution of all interviewees' job search behaviors is presented in Table 2.

Table 2 shows that interviewees who relied solely on the informal channel constitute the smallest portion of the interviewees (7\%). The common use of social contacts was 229 seen in various combinations with formal job search methods, making up $43 \%$ of the 230 total interview cases. It should be pointed out that the analysis centers on the job seekers' perceptions of and reactions to the employers' hiring methods. This is because the purpose of this study is to explore the variation of individual job search behaviors, which makes it necessary to examine individual job seekers' perceptions of employers' hiring requirements and their subsequent strategies within various employment contexts.

\section{The use of the formal channel alone in both recruitment and selection}

Studies from the perspective of human capital often hold the assumption that a job search is driven solely by the match between a job seeker's certifiable qualifications and an employer's expectation of the individual's productivity (Becker 1993). From this perspective, empirical studies in the United States (Alon and Tienda 2007) and the United Kingdom (Goodman et al. 1997; Themelis 2008) show that the importance of education in career success has proven to remain significant; moreover, this positive impact has become increasingly strong over time.

The story of Ms. Hua Lu's ${ }^{1}$ job search is a clear illustration of the importance of certifiable qualifications in an increasingly competitive labor market. Hua, a 33-year-old assistant professor at the time of the interview, entered her workplace in 2003, an academy that was designated by the central government to train high-rank governmental officials and cultivate the future leadership of the Chinese Communist Party. Due to the academy's direct affiliation with the central government and its unique advantage in providing easy access to high-status governmental officials, positions in this academy are often open only to applicants who have been recommended by internal referrers. As Hua observed, "the interviewers pay more attention to applications recommended by someone they knew." However, with a Ph.D. degree obtained from the best program in the country, Hua's educational achievement caught the interviewers' attention and earned her an interview opportunity. In the multi-step selection process that followed, which involved individual interviews, group interviews, and a job talk, Hua's outstanding performance positioned her in the first place among all applicants for all positions offered by the academy in that year. Hua successfully landed a highly competitive position solely through the formal channel, even though hiring usually relied on the internal referral system in her workplace. As Hua commented, "I think our department head needed someone to do real work. If he had hired some people through guanxi, he couldn't get the work done." "Getting real work done" implies that the requirements of this particular job position were mainly certifiable. As a result, certifiable qualifications were preferred over noncertifiable qualifications in both the recruitment and selection stages, leading to a greater chance of job search success solely through the formal channel on the job seeker's side.

\section{The use of the informal channel alone in both recruitment and selection}

The case of Mr. Jie Wang, the 23-year-old leader of a security team in a gated community presents the opposite story to Hua's experience. After dropping out of school 
in the ninth grade, Jie had a difficult time to find a job. In 2003, Jie's brother discovered that a former classmate was working as the head of the maintenance team in this gated community. With help from the maintenance team leader, Jie was introduced to the head of the security team. Upon the security team leader's approval, Jie was hired as a security guard and has "worked his way up" (quoted from Jie's interview transcript) ever since.

In Jie's case, the company did not make an effort to recruit security guards publicly; instead, job vacancies were filled mainly through existing employees' recommendations. The use of employee referrals is the cheapest way to obtain labor. Although its main disadvantage lies in the inability to generate a large candidate pool due to the homophily principle of contact use (Fernandez et al. 2000; Fernandez and Weinberg 1997; Rees 1966), the use of the internal referral system is ideal when certifiable qualifications are not a concern of the employer. In addition to reducing costs by a large margin in both the recruitment and selection stages, the use of internal referrals also increases the new employee's loyalty to the employer and reduces the turnover rate by tying the new worker's performance to the interests and reputation of his or her sponsor (Jenkins 1984; Petersen et al. 2000). In short, for a security guard position, non-certifiable qualifications such as trustworthiness, sense of responsibility, and willingness to help homeowners are emphasized more than certifiable qualifications such as education. When a job mainly requires non-certifiable qualifications, the employer's hiring methods tend to be informal in both recruitment and selection. In this scenario the sole reliance on the use of the informal channel would work the best.

The use of the formal-informal joint channel between two hiring stages Formal recruitment with informal selection

In a case study on manufacturing workers' employment in South Wales during the 1950s, Fevre (1989) found that employers publicized job information using posts and newspaper advertisements only when the labor supply was not sufficient. After a proper size of a candidate pool was generated through formal recruitment methods, employers would then make final hiring decisions through internal referrals. Those who had family members or relatives working in the same factory were significantly more likely to be hired. According to Fevre (1989), employers aimed to attract as many qualified applicants as possible at the recruitment stage in order to relieve the labor supply shortage. Once employers reached a large pool of candidates, their focus turned to applicants' non-certifiable qualifications (such as values of hard work and loyalty to the employer) and subsequently changed to select employees whose work ethic could be vouched for by the existing employees.

It is noticeable that this job-person matching pattern of formal recruitment followed by informal selection was not found in my interview data. This is because the labor shortage context described in Fevre's (1989) study was drastically different from the employment environment in China in the past decades, where the size of the labor force had far outgrown the number of available jobs. For lower-end jobs, labor shortage had seldom been an issue in urban China at least up to 2003, due to the influx of migrant peasant workers to cities for non-agricultural job opportunities (Lu and Pun 2010). If a job position required mainly non-certifiable qualifications, the employer would use the 
informal channel in both recruitment and selection stages since "pumping up" the candidate pool by formal means would not be necessary due to labor oversupply. For higherend jobs, on the other hand, job requirements of certifiable qualifications had been elevated by the increasingly intensified competition among qualified job candidates. According to one report (Cai et al. 2009) issued by the government-controlled media, for example, the first-time employment rate among university graduates had decreased over time and remained about $70 \%$ since the beginning of this century. The lack of the pattern of "formal recruitment with informal selection" in my interview data thus shows that within the context of labor oversupply in urban China, especially the oversupply of the highly educated labor force, certifiable qualifications cannot be completely overlooked in the selection stage.

\section{Informal recruitment with formal selection}

The case of Mr. Lei Yang, a 40-year-old departmental manager in a foreign-invested company, illustrates this type of job search behavior. Prior to entering his current company, YT, which operates the largest-scale container terminals in the local harbor, Lei had many years of work experience and a master's degree in his field from a prestigious university. Driven by his career ambition, Lei set the goal of getting a managerial position in YT, the leading company of his field. However, as he observed, "such positions would never be publicly advertised." Lei thus asked a senior schoolmate, a senior manager working in the same industry in the same city, to call the manager of the R\&D department in YT and recommend him. This recommendation directly led Lei into a two-step selection process in which Lei's outstanding interview performance impressed his interviewers, the middle-level departmental manager, and the top-level general manager of the company. Lei was then hired as an associate manager in the R\&D department of YT in 2001.

Unlike jobs that only require entry-level certifiable qualifications, the R\&D managerial position in YT needed outstanding, highly specialized knowledge that could not easily be measured by educational degrees or years of work experience. Since publicly advertising this position would most likely generate an enormous pool of entry-level candidates with a small chance of reaching the very few truly qualified candidates, the employer considered formal recruitment methods to be inefficient. By contrast, through a professional, third party's recommendation, the employer could reach a promising candidate directly. Lei's case thus supports Fernandez and Weinberg's (1997) argument that the use of the referral system is the employer's strategy of taking advantage of social ties to reach suitable candidates at a relatively low cost. To make a hiring decision, the company must still scrutinize a candidate's qualifications by formal means, since certifiable rather than non-certifiable qualifications matter most for a highly specialized managerial position.

\section{The use of the formal-informal joint channel within two hiring stages}

In her ethnographic observation of how unemployed Scottish workers obtained jobs at steel factories in Central England, Grieco (1987) noticed that there was no distinct boundary between formal and informal methods in matching Scottish workers with job opportunities. The employers' hiring strategy-reliance on state-run employment agencies-was supposedly formal. However, instead of publicizing job information broadly 
so as to attract potentially qualified candidates in a broad range, the agencies chose to minimize the amount of information available on the market. "The kin-and-friends channel through the importance of internal notification procedures and word-of-mouth spread of information" (Grieco 1987, 121) became the major channel in the recruitment process. Likewise, at the following selection stage, those who had relatives or friends working in the factories were more likely to get hired.

The unique situation of hiring workers from distant geographic locations makes it necessary to adopt formal methods in this job-person matching scenario. At the recruitment stage, it would not be easy for employers to reach new workers through the informal channel due to the geographic distance. By contrast, massive recruitment in a remote location could be conducted with significantly lower costs by relying on the assistance of state-run employment agencies. At the selection stage, the use of state-run employment agencies could increase the accountability of a hiring decision, particularly when the employers had little knowledge about the region where job candidates were from. Also, because the employers' top concern was whether or not employees were hardworking and willing to stay in the job, which were non-certifiable qualifications, informal recruitment and selection strategies were incorporated into a supposedly formal hiring process run by public employment agencies. Consequently, successful job seekers were those who had both formal accesses to these employment agencies and informal recommendations from existing employees.

While Grieco's (1987) study describes how formal and informal job-person matching methods were utilized to fill lower-end, manual worker positions, the case of Mrs. Yun Chen, a 30-year-old office head working in a branch office of a state-owned bank, shows how the formal-informal joint channel plays a significant role in matching well-educated candidates with higher-end jobs in China's labor market. Before her graduation from a prestigious master's program in finance in 2002, Yun managed to contact a senior manager who was affiliated with the hiring bank through a good friend's husband. As she stated: "There were so many applicants. Everyone holds a Bachelor's or Master's degree in economics, finance, or other relevant disciplines. If you want to make your resume stand out, you must have someone [important to the bank] put in a good word for you."

Yun's remarks have two implications. First, every applicant needs to hold a bachelor's or master's degree in relevant disciplines in order to be eligible to apply for job positions in the bank. Second, an applicant referred by a high-status contact related to the bank would have a significantly greater possibility of getting through the recruitment stage. The first implication indicates that certifiable qualifications (in this case, suitable educational degrees) certainly determine whether or not one is eligible to apply for a position in the bank. The second implication shows that under the premise that every applicant who possesses certifiable qualifications that satisfy the bank's basic hiring requirements, the bank recruiters would turn their focus to applicants' non-certifiable qualifications. "I was told by my reference that the bank wouldn't hire those who like to stand out, because a bank doesn't need this type of people. The work at a bank is not necessarily challenging. So, he [the reference] recommended me as a good employee who was down to earth and willing to do tedious work." ${ }^{2}$ Non-certifiable qualifications, such as willingness to do long-term, tedious work, can hardly be evaluated reliably by formal means. Getting a high-status internal contact to vouch for her work ethic thus played 
an essential role in Yun's job search success. Moreover, receiving inside information about what type of candidates the bank would prefer also significantly improved Yun's performance in the selection stage. After passing one written test and two rounds of interviews with different levels of bank managers, Yun eventually received a job offer from her current bank. When asked about what qualifications were most important in her job search process, Yun said: "Now, when I look back, I can clearly see everything matters. Your expertise and specialty have to be qualified first; otherwise, you cannot even get into the game. Your reference is equally important; without a reference, you cannot survive the game, regardless of your degree."

In the case of the bank's hiring practice, the formal channel-public recruitment followed by a written test and interviews-was used to gauge candidates' certifiable qualifications, while the internal referral system was adopted to evaluate candidates' non-certifiable qualifications. The extent to which a candidate's non-certifiable qualifications matched the bank's hiring requirements was assessed through the candidate's connection with the bank, shown by the reference's guanxi with the bank and the candidate's guanxi with the reference. The higher the reference's status within the bank system, the stronger the guanxi was between the reference and the bank, and thus the more reliable the recommendation was about the candidate's non-certifiable qualifications. The closer the guanxi between the applicant and the reference, the better the reference knew the applicant, and thus the more detailed information the internal recommendation would contain about the candidate's non-certifiable qualifications. A hiring decision was eventually made based on an integrative calculation of an applicant's certifiable qualifications (shown via objective evaluations of the applicant's resume, as well as performance in the test and interviews) and non-certifiable qualifications (through evaluating the applicant's references).

\section{The match between individual qualifications and job search channels}

By contextualizing individual job search behavior in various job-person matching scenarios, the qualitative analysis explains how the variation in hiring requirements embedded in different positions differentiates the employer's hiring methods, which in turn directs individual job search behavior into the channel corresponding to the employer's hiring methods. From this approach, it is clear that the formal, informal, and formal-informal joint channels suit essentially different jobperson matching scenarios, in which different types of qualifications are highlighted. In this section, I thus adopt quantitative analysis to generalize this finding at the population level.

I distinguish two types of qualifications. Individuals' certifiable qualifications commonly include educational degrees, transcripts, expertise certificates, occupational licenses, and work experience. Membership in the Communist Party could serve as an additional type of certifiable qualification in China's context, particularly when an individual seeks job opportunities in the public sector. Joining the party was once the symbol of one's merits in the communist era. Although the ideological importance of being a party member has faded since the socioeconomic transition began, the importance of political credentials has persisted, particularly when it came to positions that exercise decision-making authority (Walder et al. 2000). For this reason, party 
membership still connotes desirable qualities in a job seeker, such as organizational and communication skills, team spirit, and the capability to get things done, as Guo (2005) argues in his study on the party's recruitment of college students in the last several decades.

Direct measurements of non-certifiable qualifications are difficult to obtain for two reasons. First, the risk of not exhausting crucial dimensions of non-certifiable qualifications is much higher than that for certifiable qualifications, since existing studies focus mainly on certifiable qualifications, particularly from the human capital perspective (Alon and Tienda 2007; Goodman et al. 1997; Themelis 2008). Second, although the roles that non-certifiable qualifications play in job searches have been documented by social psychologists (Barber et al. 1994; Boswell et al. 2012; Kanfer et al. 2001), the extent to which each non-certifiable qualification contributes to individual job search success remains unclear. Therefore, family status origin is used as a proxy for non-certifiable characteristics because the formation of one's disposition, habits, behaviors, values, and other characteristics related to noncertifiable qualifications starts at the beginning of the socialization process. Parents have the greatest influence in this process, as shown in life course studies (Brown et al. 2006; Warren et al. 2002).

I thus hypothesize that the distinction between the formal-informal joint channel and the two types of single channels is necessary because individuals who adopt the joint channel possess qualifications essentially different from those who adopt either type of the single channel. Namely,

Hypothesis: The variation of individual qualifications differentiates job search methods. More specifically,

Hypothesis a: An individual with high-level certifiable qualifications but low-level non-certifiable qualifications is likely to only use the formal job search channel. Hypothesis b: An individual with high-level non-certifiable qualifications but low-level certifiable qualifications tends to only use the informal job search channel. And, Hypothesis c: Only when an individual possesses both certifiable and non-certifiable qualifications does the use of the formal-informal joint channel become more likely.

\section{Data and measurements}

Quantitative data were drawn from the 2003 CGSS-Urban Section. The sample consists of 5894 adults, aged 18 to 69 years old, who were randomly selected from 28 provincial-level locations. Retrospective information was collected about all job search methods the respondent used prior to job entry in the current workplace. Descriptive analysis of the quantitative data is shown in Appendix 2.

Among all job search methods reported by respondents, the options "getting help from parents/relatives," "recommendation from others," and "others offered a job without asking" were coded as informal job search methods. The remaining options were coded as formal job search methods. Those were "assigned by the government or arranged by some official organization," "internal recruitment in a state-owned organization," "direct application," "employment services in the market," "human resources exchange center," "self-employed," and "job entry examination." Based on all reported methods, respondents' 
job search behaviors were coded into three categories: the formal-informal joint channel, the formal channel only, and the informal channel only. ${ }^{3}$

Certifiable qualifications, as aforementioned, were education (measured by years), party membership (with party members coded one and non-party members coded zero), and years of work experience. Regarding family status origin, father's education and party membership were selected as the indicators. Parental education has long been documented as exerting the foremost impact on an individual's socialization process (Blau and Duncan et al. 1967; Warren et al. 2002). Meanwhile, in China, parents' political values also significantly impact the formation of the individual's characteristics related to non-certifiable qualifications (Zang 2003). Considering the patriarchal culture in Chinese society, father's education and party membership were thus used as indicators of family status origin. In addition, gender, age, and era of job entry were included as control variables.

\section{Results}

The $t$ test was first used to compare group-mean differences of each qualification indicator among respondents who used one of the three job search channels. As Table 3 presents, when education, party membership, and years of work experience were used as measures of certifiable qualifications, the group of respondents who solely used the informal channel displayed no significant advantage in certifiable qualifications. Individuals who used the joint channel had the highest average educational achievement- 0.2 years more than the average education of formal-channel-only users and 0.6 years more than informal-channel-only users. In terms of party membership, the percentage of party members was highest in formal-channel-only users-about $3 \%$ higher than joint-channel users and about $8 \%$ higher than informal-channel-only users. As for years of work experience, the only significant group-mean difference was between joint-channel users and formal-channel-only users, with the average work experience of the former being 0.7 years more than that of the latter.

Table 3 t-test of group-mean differences in qualification measures among three types of job search behaviors, CGSS Urban Section, 2003

\begin{tabular}{llll}
\hline Job seeker's characteristics & Formal only-informal only & Joint use-formal only & Joint use-informal only \\
\hline Education & $0.37^{\mathrm{a}}$ & $0.217^{\mathrm{b}}$ & $0.587^{\mathrm{a}}$ \\
& $(0.115)$ & $(0.111)$ & $(0.132)$ \\
Party membership & $0.076^{\mathrm{a}}$ & $-0.029^{\mathrm{c}}$ & $0.047^{\mathrm{a}}$ \\
& $(0.012)$ & $(0.011)$ & $(0.012)$ \\
Years of work experience & -0.149 & $0.717^{\mathrm{b}}$ & 0.568 \\
& $(0.345)$ & $(0.320)$ & $(0.408)$ \\
Father's highest education & $-0.392^{\mathrm{b}}$ & $0.937^{\mathrm{a}}$ & $0.545^{\mathrm{c}}$ \\
& $(0.169)$ & $(0.157)$ & $(0.199)$ \\
Father's party membership & -0.006 & $0.059^{\mathrm{a}}$ & $0.052^{c}$ \\
& $(0.016)$ & $(0.015)$ & $(0.020)$ \\
\hline
\end{tabular}

${ }^{a}$ Significant at $0.1 \%$

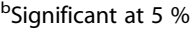

'Significant at $1 \%$ 
However, when it comes to non-certifiable qualifications, formal-channel-only users had no significant advantage. With father's educational achievement used as the first proxy for one's family status origin (which directly shapes one's noncertifiable qualifications), joint-channel users reported the highest level of father's education-on average 0.5 years more than informal-channel-only users, and 0.9 years more than formal-channel-only users. Regarding father's party membership, it is interesting that joint-channel users enjoyed a significant advantage over the other two groups. The percentage of father being a party member in joint-channel users was about $6 \%$ higher than formal-channel-only users and about $5 \%$ higher than informal-channel-only users.

The above group-mean differences in each of the qualification measures in Table 3 show that: 1) the group of formal-channel-only users showed significant advantages in certifiable but not non-certifiable qualifications; 2) the group of informal-channel-only users showed significant advantages in non-certifiable but not certifiable qualifications; and 3), joint-channel users enjoyed the greatest advantages in both certifiable and noncertifiable qualifications. A multinomial regression model was further used to examine the extent to which individual job seekers' qualifications were matched up with their use of job search channels.

Table 4 presents odds ratios of all three combinations among the three types of job search channels. Education increased one's chance of using the formal channel the most, followed by the chance of using the joint channel. Other covariates being equal, each 1-year increase in education increased the likelihood of using the formal channel by $10 \%$ and that of using the joint channel by $6 \%$, relative to the likelihood of using the informal channel. Being a party member doubled one's chance of using

Table 4 Multinomial logistic regression on three types of job search behaviors, CGSS Urban Section, 2003

\begin{tabular}{|c|c|c|c|c|c|c|}
\hline \multirow[b]{2}{*}{ Education in years } & \multicolumn{2}{|c|}{$\begin{array}{l}\text { Formal only vs. } \\
\text { informal only }\end{array}$} & \multicolumn{2}{|c|}{$\begin{array}{l}\text { Joint channel vs. } \\
\text { formal only }\end{array}$} & \multicolumn{2}{|c|}{$\begin{array}{l}\text { Joint channel vs. } \\
\text { informal only }\end{array}$} \\
\hline & $1.100^{\mathrm{a}}$ & $(0.016)$ & $0.959^{b}$ & $(0.016)$ & $1.055^{\mathrm{c}}$ & $(0.019)$ \\
\hline Party membership & $1.994^{\mathrm{a}}$ & $(0.201)$ & 0.740 & $(0.161)$ & 1.475 & $(0.232)$ \\
\hline Years of work experience & $0.945^{c}$ & $(0.020)$ & $1.050^{\mathrm{b}}$ & $(0.019)$ & 0.992 & $(0.024)$ \\
\hline Years of work experience squared & 1.001 & $(0.001)$ & 0.999 & $(0.001)$ & 1.000 & $(0.001)$ \\
\hline Father's highest education & 0.999 & $(0.012)$ & $1.021^{b}$ & $(0.010)$ & 1.020 & $(0.0131)$ \\
\hline Father's party membership & 1.158 & $(0.110)$ & 1.069 & $(0.098)$ & 1.238 & $(0.125)$ \\
\hline \multicolumn{7}{|l|}{ Control variables } \\
\hline Female & $0.820^{b}$ & $(0.095)$ & 0.914 & $(0.089)$ & $0.750^{c}$ & $(0.111)$ \\
\hline Age & $1.143^{c}$ & $(0.043)$ & 0.952 & $(0.043)$ & 1.088 & $(0.052)$ \\
\hline Age squared & 0.999 & $(0.001)$ & 1.000 & $(0.001)$ & 0.999 & $(0.001)$ \\
\hline \multicolumn{7}{|l|}{ Job entry era (ref: before 1979) } \\
\hline Job entry between 1979 and 1992 & $0.305^{\mathrm{a}}$ & $(0.150)$ & $2.575^{\mathrm{a}}$ & $(0.135)$ & 0.785 & $(0.146)$ \\
\hline Job entry after 1992 & $0.140^{a}$ & $(0.159)$ & $5.199^{a}$ & $(0.142)$ & 0.730 & $(0.140)$ \\
\hline Constant & 0.509 & $(0.553)$ & 0.402 & (0.599) & $0.205^{b}$ & $(0.143)$ \\
\hline Observations & 4,892 & & 4,892 & & 4,892 & \\
\hline
\end{tabular}

Odds ratios are presented. Robust standard errors are in the parentheses. Cases with missing values were deleted ${ }^{\text {a }}$ Significant at $0.1 \%$

${ }^{b}$ significant at $5 \%$

csignificant at $1 \%$ 
the formal channel relative to that of using the informal channel, with covariates controlled. After the quadratic term of years of work experience was controlled along with other covariates, each 1-year increase in one's work experience increased the likelihood of using the informal channel by $6 \%$ and that of using the joint channel by $5 \%$, relative to the chance of using the formal channel only. The difference between the chance of using the informal channel and that of using the joint channel caused by work experience was not significant. As for family status origin, other covariates being equal, each 1-year increase in father's education increased one's possibility of using the joint channel versus the formal channel by $2 \%$. Father's party membership showed the tendency of facilitating one's use of the joint channel relative to the informal channel, though this trend was only marginally significant. Overall, the significant effects of two types of qualification measures in Table 4 show that: 1) certifiable qualifications increase one's possibility of using the formal channel and 2) non-certifiable qualifications facilitate the use of the joint channel rather than the use of the informal channel alone.

Beyond this, there are other factors that play equally important roles in an individual's decision on job search strategies. For example, women were significantly more likely to adopt the informal channel relative to the use of either the formal or joint channel, which implies the great impact of the patriarchal culture on women's employment in Chinese society. Effects of age and era of job entry reflected the significant changes in individual job search behaviors within the context of China's transitional economy. With the quadratic term of age as well as other covariates controlled, age had a significant impact on one's chance of using the formal channel versus the informal channel, since every 1-year increase in one's age increased this odds ratio by $14 \%$. In other words, the older the job seeker was, the more likely it would be for the job seeker to adopt the formal channel, suggesting the influence of the previously dominant state-controlled job assignment system on older generations' job search behaviors. Furthermore, the later the job seeker entered the current workplace, the less likely it would be for the job seeker to adopt the formal channel compared to using either the informal or the joint channel, suggesting the growing importance of social contacts in job search success in the formation process of a free labor market in China.

Despite the significant cohort effects as well as impacts of social changes shown by the effects of age and job entry era, results from Table 4 confirm the match between job seekers' qualifications and their use of job search channels. Indeed, job seekers with both certifiable and non-certifiable qualifications were more likely to adopt the formalinformal joint channel. Thus, the fact that their use of social contacts leads to job search success may not be considered an advantage of using contacts alone relative to using the formal job search channel alone; rather, it shows that the informal channel (mainly indicated by assistance from social contacts) has a positive impact on job search outcomes only when used in combination with the formal channel.

\section{Conclusion and discussion}

From the perspective of matching individual qualifications with hiring requirements of job positions, this paper articulated the necessity of distinguishing the formal-informal 
joint channel as a third type of job search behavior, independent from the sole reliance on either the formal or informal job search channel. Focusing on the employer's hiring requirements, my typology of the theoretical distribution of job search behaviors shows that neither the formal nor informal channel is the most commonly adopted method. Using concrete job-person matching cases collected in China's changing employment context and ethnographic case studies in the existing literature, each type of job search behavior derived from the typology was illustrated. Unlike the conventional approach that often dichotomizes individual job search behaviors into either the formal or informal group, this study shows that the formal-informal joint channel is most frequently seen in urban Chinese job seekers' search behaviors. Because certifiable and noncertifiable qualifications are often both required by a job position, the formal-informal joint channel rather than either the formal or informal job search channel alone leads to a better chance of job search success.

The quantitative analysis based on data drawn from the 2003 CGSS confirms this speculation at the population level. Individuals with the highest degree of certifiable but low degree of non-certifiable qualifications tend to solely use the formal channel. Individuals with both certifiable and non-certifiable qualifications tend to use the formal and informal job search methods jointly. Those with low certifiable qualifications tend to rely only on the informal channel. This is not because they have a high level of non-certifiable qualifications. As shown in Table 4, non-certifiable qualifications do not increase the likelihood of solely using the informal channel, but that of using the formal and informal methods jointly. In other words, sole reliance on the informal channel is usually not due to a high level of non-certifiable qualifications, but instead is often due to the lack of competitive, particularly certifiable, qualifications. This explains the puzzle in the existing studies regarding the high frequency of contact use among the disadvantaged in the labor market, despite the few resources conveyed through their social ties (Lin 1999, 2001).

This study has several theoretical implications in the fields of job search, social capital, and stratification and mobility. First of all, although it is an individual behavior, job search is directly confined by the external employment environment, particularly regarding job positions available in the labor market. For this reason, job search should not be studied as a purely individual behavior, but rather is better understood from an approach that situates job search in the context of employers' hiring requirements.

Among studies about the role social capital plays in job seeking, second, by examining formal and informal job search as competing behaviors, social capital scholars have long been challenged by the issue of causality. Indeed, social capital is endogenous to other characteristics, such as certifiable qualifications. It is always questionable whether the observed positive association between contact use and job search outcomes reflects a causal relationship or a spurious correlation resulting from one's certifiable qualifications (Mouw 2003). This study exemplifies a new approach to addressing this puzzle by distinguishing the joint use of the formal-informal channel from sole reliance on contact use. This study demonstrates the positive effects of social capital not among job seekers who solely relied on contact use but among those who could combine contact use with formal job search methods. This finding thus confirms the characteristic of endogeneity of social capital. 
Finally, by using family status origin as the proxy for one's non-certifiable qualifications, this study also indicates the important role one's class origin plays in the reproduction and reinforcement of social status. Different from Blau and Duncan's (1967) seminal study about family status origin's positive association with one's educational attainment (namely, certifiable qualifications), this study echoes Bourdieu's (1987) concept of social capital by linking one's non-certifiable qualifications to family status origin. That is, family status origin matters for an individual's status attainment, not only due to its significant impact on this individual's acquisition of certifiable qualifications but also because of its essential role in shaping one's noncertifiable qualifications. Consideration of the multidimensional influences of one's family status origin on status attainment is much needed in future studies.

Nevertheless, this study is not without its limitations. This study examined job seekers' perceptions of employers' hiring requirements, rather than the employers' hiring requirements directly. Although it is important to understand how a job seeker perceives and reacts in a specific job-person matching scenario, data available at the organizational level would be valuable for a study focused on the job-person matching process. Also, although family status origin was used as the proxy for non-certifiable qualifications in this study, challenges remain regarding measuring non-certifiable qualifications in a more direct, reliable, and exhaustive manner. Finally, due to the scarcity of information about the use of the formal-informal joint job search channel in the majority of the existing surveys, this study was based on the 2003 CGSS with an exclusive focus on urban Chinese job seekers with legal residency status in their local areas. A broader discussion that includes rural migrant workers in China's labor market, as well as labor markets in other societal contexts, is indispensable in order to examine a full range of the distribution of individual job search behaviors.

Overall, by articulating both theoretically and empirically the necessity of distinguishing the formal-informal joint channel from the sole use of either the formal or informal channel, this study provides a new approach to understanding the effects of contact use in job searches. As Granovetter has long pointed out, "the formal and informal routes to jobs, which we keep distinct in our statistics, get blurred in actual daily practice." (Granovetter 1995, 168) Unlike conventional job search studies that follow a dichotomous assumption on a clear distinction between formal and informal job search behavior, this study highlights the formal-informal joint channel as the most commonly seen job search behavior in practice. Because both certifiable and non-certifiable qualifications are often required, job seekers possessing both qualifications often tend to combine formal and informal job search methods. By doing so, they gain a better chance to succeed in job searches. Indeed, their certifiable qualifications may not be at the top level but are sufficient to meet the employer's hiring requirements. Meanwhile, they are also able to demonstrate their non-certifiable qualifications by mobilizing their social contacts. Therefore, the use of social contacts indeed facilitates one's job search success, but very often in combination with the use of formal job search methods. By highlighting the essential differences between joint channel users and those who rely on contact use alone, this study serves as a preliminary attempt to establish a new approach that better reflects individual job search behaviors in reality. More scholarly attention is much 
needed in this line of research to further explore the roles formal and informal job search methods play jointly in job seeking activities.

\section{Endnotes}

${ }^{1}$ All names used in this study are pseudonyms to protect interviewees' confidentiality. ${ }^{2}$ Quoted from Yun's interview transcript.

${ }^{3}$ To verify the information, each respondent was also asked how they collected job information and whether or not they received help from someone else in the process of obtaining their current job. If a respondent did not report any informal job search methods in the first question, but reported using informal connections for collecting job information and/or getting help from someone else for job acquisition, this case would be re-coded from "formal channel only" to "formal-informal joint channel."

\section{Appendix}

\section{Appendix 1}

Table 5 Descriptive statistics of qualitative data

\begin{tabular}{|c|c|c|}
\hline Variables & Values & $\overline{\text { Percentage }}$ \\
\hline \multirow[t]{4}{*}{ Era of job entry } & $<1979$ & 11 \\
\hline & 1979-1991 & 14 \\
\hline & 1992-1997 & 21 \\
\hline & 1998-2003 & 54 \\
\hline \multirow[t]{3}{*}{ Location } & Beijing & 36 \\
\hline & Shenzhen & 32 \\
\hline & Jiangyou & 32 \\
\hline \multirow[t]{3}{*}{ Type of sector } & Party, governmental, and public & 25 \\
\hline & State-owned enterprises & 36 \\
\hline & Market sector & 39 \\
\hline \multirow[t]{2}{*}{ Party membership } & Party members & 48.5 \\
\hline & Non-party members & 51.5 \\
\hline \multirow[t]{4}{*}{ Years of education } & Less than 6 years & 15.2 \\
\hline & 6-12 years & 21.2 \\
\hline & $13-16$ years & 15.2 \\
\hline & Over 16 years & 48.4 \\
\hline \multirow[t]{2}{*}{ Father's party membership } & Party members & 48.5 \\
\hline & Non-party members & 51.5 \\
\hline \multirow[t]{4}{*}{ Father's education } & Less than 6 years & 36.4 \\
\hline & $6-12$ years & 33.3 \\
\hline & $13-16$ years & 18.2 \\
\hline & Over 16 years & 12.1 \\
\hline \multirow[t]{2}{*}{ Gender } & Male & 57.6 \\
\hline & Female & 42.4 \\
\hline \multirow[t]{3}{*}{ Age } & Below 30 & 42.4 \\
\hline & $30-40$ & 30.3 \\
\hline & Over 40 & 27.3 \\
\hline
\end{tabular}




\section{Appendix 2}

Table 6 Descriptive statistics of all used variables, CGSS 2003, Urban Section

\begin{tabular}{|c|c|c|c|c|c|}
\hline Variables & Categories & Percent & Mean & S.D. & Number \\
\hline \multirow[t]{4}{*}{ Job search channels } & Joint channel & 21.04 & & & 1097 \\
\hline & Formal only & 61.74 & & & 3220 \\
\hline & Informal only & 17.22 & & & 898 \\
\hline & Total & 100 & & & 5215 \\
\hline \multicolumn{6}{|l|}{ Certifiable qualifications } \\
\hline Education (years) & & 7.73 & 6.37 & 5894 & \\
\hline \multirow[t]{4}{*}{ Party membership } & Non-members & 88.94 & & & 5236 \\
\hline & Members & 9.2 & & & 542 \\
\hline & Missing & 1.97 & & & 116 \\
\hline & Total & 100 & & & 5984 \\
\hline Years of work experience & 6.23 & 9.09 & 5232 & & \\
\hline Years of work experience squared & 121.41 & 259.95 & 5232 & & \\
\hline \multicolumn{6}{|l|}{ Non-certifiable qualifications } \\
\hline Father's education (years) & 6.5 & 3.85 & 5593 & & \\
\hline \multirow[t]{4}{*}{ Father's party membership } & Non-members & 73.18 & & & 4313 \\
\hline & Members & 23.09 & & & 1361 \\
\hline & Missing & 3.73 & & & 220 \\
\hline & Total & 100 & & & 5994 \\
\hline \multicolumn{6}{|l|}{ Other factors } \\
\hline \multirow[t]{3}{*}{ Gender } & Females & 51.9 & & & 3059 \\
\hline & Males & 48.1 & & & 2835 \\
\hline & Total & 100 & & & 5894 \\
\hline Age & & & 26.496 & 9.324 & 5220 \\
\hline Age squared & & 788.95 & 63.451 & 5220 & \\
\hline \multirow[t]{5}{*}{ Era of job entry } & Before 1979 & 24.18 & & & 1425 \\
\hline & Between 1979 and 1992 & 30.61 & & & 1804 \\
\hline & After 1992 & 34.17 & & & 2014 \\
\hline & Missing & 11.05 & & & 651 \\
\hline & Total & 100 & & & 5894 \\
\hline
\end{tabular}

\section{Competing interests}

The authors declare that they have no competing interests.

\section{Authors' contributions}

JS collected the interview data, conducted both the qualitative and quantitative analyses, and drafted as well as finalized the manuscript independently. All authors read and approved the final manuscript.

\section{Acknowledgements}

This study was supported by the Postdoctoral Fellowship generously provided by the Prentice Institute for Global Population and Economy, University of Lethbridge, Canada. I thank Bonnie Erickson, Eric Fong, Alexandra Marin, Deborah Davis, and Robert Andersen for their helpful comments on early drafts of this study. I am also grateful to Susan McDaniel for her kind support in the process of accomplishing this paper. Direct correspondence to Jing Shen, the Prentice Institute for Global Population and Economy, University of Lethbridge, 4401 University Drive West, Suite L1184, Lethbridge, Alberta, T1K 3M4 Canada. Telephone: 1-(416)-261-6198 E-mail: jing.shen@uleth.ca.

Received: 13 January 2015 Accepted: 20 May 2015

Published online: 05 June 2015 
References

Alon, Sigal, and Marta Tienda. 2007. Diversity, opportunity, and the shifting meritocracy in higher education. American Sociological Review 72: 487-511.

Barber, Alison E, Christina Daly, Cristina Giannantonio, and Jean M Phillips. 1994. Job search activities: an examination of change over time. Personnel Psychology 47: 739-766.

Bian, Yanjie. 1997. Bringing strong ties back in: indirect connection, bridges, and job search in China. American Sociological Review 62(3): 266-285.

Bian, Yanjie, and Soon Ang. 1997. Guanxi networks and job mobility in China and Singapore. Social Forces 75: 981-1005.

Bian, Yanjie, Ronald Breiger, Deborah Davis, and Joseph Galaskiewicz. 2005. Occupation, class, and social networks in urban China. Social Forces 83: 1443-1468.

Blau, Peter M, and Duncan Otis Dudley (with the collaboration of Andrea Tyree). 1967. The American occupational structure. New York: Wiley.

Becker, GS. [1964] 1993. Human capital: a theoretical and empirical analysis, with special reference to education, 3rd ed. Chicago, L: University of Chicago Press.

Boswell, Wendy, Ryan Zimmerman, and Brian Swider. 2012. Employee job search: toward an understanding of search context and search objectives. Journal of Management 38: 129-163.

Bourdieu, Pierre. 1987. (Translated by Richard Nice.) Distinction: a social critique of the judgement of taste. Cambridge: Harvard University Press.

Boxman, Ed, Paul de Graaf, and Hendrik Flap. 1991. The impact of social and human capital on the income attainment of Dutch managers. Social Networks 13: 51-73.

Brown, Douglas J, Richard T Cober, Kevin Kane, Paul E Levy, and Jarrett Shalhoop. 2006. Proactive personality and the successful job search: a field investigation with college graduates. Journal of Applied Psychology 91: 717-726.

Cai, Fang, Du Yang, and Wang Meiyan. 2009. Employment and inequality outcomes in China. OECD Directorate for Employment, Labor and Social Affairs (ELS) and OECD Development Center (DEV) Seminar.. Retrieved February 12, 2014. (http://www.oecd.org/els/emp/42546043.pdf).

Campbell, Karen, and Rachel Rosenfeld. 1985. Job search and job mobility: sex and race differences. Research in the Sociology of Work 3: 147-174.

Erickson, BH. 2001. Good networks and good jobs: the value of social capital to employers and employees. In Social capital: theory and research, ed. N Lin, RS Burt, and K Cook, 127-157. New York: Aldine de Gruyter.

Fernandez, RM, E Castilla, and P Moore. 2000. Social capital at work: networks and employment at a phone center. American Journal of Sociology 105: 1288-1356.

Fernandez, RM, and N Weinberg. 1997. Sifting and sorting: personal contacts and hiring in a retail bank. American Sociological Review 60: 883-902.

Fevre, Ralph. 1989. Informal practices, flexible firms and private labour markets. Sociology 23: 91-109.

Flap, Hendrik, and Ed Boxman. 1999. Getting a job as a manager. In Corporate social capital and liability, ed. T Roger, AJ Leenders, and SM Gabbay, 161-179. Boston: Kluwer.

Goodman, A, R Blundell, L Dearden, and H Reed. 1997. Higher education, employment and earnings in Britain. London: London Institute for Fiscal Studies.

Granovetter, Mark S. 1973. The strength of weak ties. American of Journal of Sociology 78: 1360-1380.

Granovetter, Mark S. 1974. Getting a job: a study of contacts and careers. Cambridge, MA: Harvard University Press.

Granovetter, Mark S. 1995. Afterword 1994: reconsiderations and a new agenda. In Getting a job: a study of contacts and careers, 2nd ed, ed. Mark S Granovetter, 139-182. Chicago, IL: University of Chicago Press.

Grieco, Margaret. 1987. Keeping it in the family: social networks and employment chance. London and New York: Tavistock Publications.

Guo, Gang. 2005. Party recruitment of college students in China. Journal of Contemporary China 14: 371-393.

Jenkins, Richard. 1984. Acceptability, suitability, and the search for the habituated worker: how ethnic minorities and women lose out. International Journal of Social Economics 11: 64-76.

Kanfer, Ruth, Connie Wanberg, and Tracy Kantrowitz. 2001. Job search and employment: a personality-motivational analysis and meta-analytic review. Journal of Applied Psychology 86: 837-855.

Lai, Gina, Nan Lin, and Stephen Leung. 1998. Network resources, contact resources and status attainment. Social Networks 20: 159-178.

Lin, Nan. 1999. Social networks and status attainment. Annual Review of Sociology 25: 467-487.

Lin, Nan. 2001. Social capital: a theory of social structure and action. New York: Cambridge University Press.

Lin, Nan, and Mary Dumin. 1986. Access to occupations through social ties. Social Networks 8: 365-386.

Lin, Nan, John C Vaughn, and Walter Ensel. 1981. Social resources and occupational status attainment. Social Forces 59: 1163-1181.

Lu, Huilin, and Ngai Pun. 2010. Unfinished proletarianization: self, anger, and class action among the second generation of peasant-workers in present-day China. Modern China 36: 493-519.

Marsden, Peter V. 1994a. The hiring process: recruitment methods. The American Behavioral Scientist 37: 979-991.

Marsden, Peter V. 1994b. Selection methods in U.S. establishments. Acta Sociologica 51: 281-301.

Marsden, Peter V, and Karen Campbell. 1990. Recruitment and selection processes: the organizational side of job searches. In Social mobility and social structure, ed. RL Breiger, 59-79. Cambridge: Cambridge University Press.

Marsden, Peter V, and Elizabeth H Gorman. 2001. Social networks, job changes and recruitment. In Sourcebook of labor markets: evolving structures and processes, ed. Ivar Berg and Arne L Kalleberg, 467-502. New York: Plenum Press.

Mouw, Ted. 2003. Social capital and finding a job: do contacts matter? American Sociological Review 68(6): 868-898.

Petersen, Trond, Ishak Saporta, and Marc-David Seidel. 2000. Offering a job: meritocracy and social networks. American Journal of Sociology 106: 763-816.

Rees, Albert. 1966. Information networks in labor markets. American Economic Review 56: 559-566.

Shen, Jing. 2014. The use of formal-informal joint channel and job search success: homophily as the premise of the causal effects of contact use. Presented at the American Sociological Association annual meeting. San Francisco: California. 
Themelis, Spyros. 2008. Meritocracy through education and social mobility in post-war Britain: a critical examination. British Journal of Sociology of Education 29: 427-438.

Volker, B, and H Flap. 1999. Getting ahead in the GDR: social capital and status attainment under communism. Acta Sociologica 42(1): 17-34.

Walder, Andrew G., Bobai Li, and Donald J. Treiman. 2000. Politics and life chances in a state socialist regime: dual career paths into the urban Chinese elite, 1949 to 1996. American Sociological Review 65(2): 191-209.

Warren, John Robert, Jennifer T Sheridan, and Robert M Hauser. 2002. Occupational stratification across the life course: evidence from the Wisconsin longitudinal study. American Sociological Review 67: 432-455.

Weber, Andrea, and Helmut Mahringer. 2008. Choice and success of job search methods. Empirical Economics 35: 153-178.

Wegener, Bernd. 1991. Job mobility and social ties: social resources, prior job, and status attainment. American Sociological Review 56: 60-71.

Zang, Xiaowei. 2003. Network resources and job search in urban china. Journal of Sociology 39: 115-129.

Zikic, Jelena, and Alan Saks. 2009. Job search and social cognitive theory: the role of career-relevant activities. Journal of Vocational Behavior 74: 117-127.

\section{Submit your manuscript to a SpringerOpen ${ }^{\circ}$ journal and benefit from:}

- Convenient online submission

- Rigorous peer review

- Immediate publication on acceptance

- Open access: articles freely available online

- High visibility within the field

- Retaining the copyright to your article

Submit your next manuscript at $\boldsymbol{\sim}$ springeropen.com 